https://helda.helsinki.fi

Physicians' views on patient participation in choice of oral anticoagulants in atrial fibrillation-a qualitative study

\title{
Aarnio, Emma
}

2019-04

Aarnio , E , Huupponen , R , Hämeen-Anttila , K, Merikoski , M , Puhakka , J \& Korhonen , M J 2019 , ' Physicians' views on patient participation in choice of oral anticoagulants in atrial fibrillation-a qualitative study ' , Basic \& Clinical Pharmacology \& Toxicology , vol. 124 , no. 4 , pp. 416-422 . https://doi.org/10.1111/bcpt.13145

http://hdl.handle.net/10138/305926

https://doi.org/10.1111/bcpt.13145

acceptedVersion

Downloaded from Helda, University of Helsinki institutional repository.

This is an electronic reprint of the original article.

This reprint may differ from the original in pagination and typographic detail.

Please cite the original version. 


\title{
Article Type: Original Article
}

\section{Physicians' views on patient participation in choice of oral anticoagulants in atrial fibrillation - a qualitative study}

Emma Aarnio

\author{
Institute of Biomedicine, University of Turku, Turku, Finland \\ School of Pharmacy, University of Eastern Finland, Kuopio, Finland
}

Risto Huupponen

Institute of Biomedicine, University of Turku, Turku, Finland

Clinical Pharmacology Unit, Turku University Hospital, Turku, Finland

Katri Hämeen-Anttila

Finnish Medicines Agency Fimea, Assessment of Pharmacotherapies, Finland

Merja Merikoski

Finnish Medicines Agency Fimea, Assessment of Pharmacotherapies, Finland

Jaana Puhakka

Department of Social Services and Health Care, City of Helsinki, Helsinki, Finland

Network of Academic Health Centers, Department of General Practice and Primary Health Care, University of Helsinki, Helsinki, Finland

Maarit J Korhonen

Institute of Biomedicine, University of Turku, Turku, Finland

Centre for Medicine Use and Safety, Faculty of Pharmacy and Pharmaceutical Sciences, Monash University, Melbourne, VIC, Australia

This article has been accepted for publication and undergone full peer review but has not been through the copyediting, typesetting, pagination and proofreading process, which may lead to differences between this version and the Version of Record. Please cite this article as doi: 10.1111/bcpt.13145

This article is protected by copyright. All rights reserved. 
Correspondence: Emma Aarnio, Institute of Biomedicine, Kiinamyllynkatu 10, FI-20520 Turku, Finland, emma.aarnio@utu.fi

(Received 18 June 2018; Accepted 2 October 2018)

Running title: Patient participation in choice of OACs

Keywords: Atrial fibrillation, Direct oral anticoagulants, Interview, Prescription of drugs, Warfarin

\section{Funding and conflict of interest}

The study was funded by the Social Insurance Institution of Finland (24/26/2015). The funder had no role in the design and conduct of the study, analysis and interpretation of the data nor in the decision to submit the manuscript for publication. EA received funding also from the Finnish Cultural Foundation and MJK from the Hospital District of Southwest Finland.

MJK and RH have received grants from the Social Insurance Institution of Finland, and RH is a member of the Advisory Board for Social and Medical Affairs of the Social Insurance Institution. JP has received lecture fees and travel grants from Orion (marketing authorization holder of warfarin in Finland). Other authors declare they have no conflicts of interest.

\footnotetext{
Abstract

Direct oral anticoagulants provide an alternative to vitamin $\mathrm{K}$ antagonists for the anticoagulation therapy in atrial fibrillation (AF). The availability of several treatment options with different attributes makes shared decision making appropriate for the choice of anticoagulation therapy. The aim of this study was to understand how physicians choose an oral anticoagulant (OAC) for patients with AF and how physicians view patients' participation in this decision. Semi-structured interviews with 17 Finnish physicians (8 general practitioners and 9 specialists) working in the public sector were
} 
conducted. An interview guide on experience, prescribing and opinions about oral anticoagulants was developed based on previous literature. The data were thematically analysed using deductive and inductive approaches. Based on the interviews, patient's opinion was the most influential factor in decision making when there were no clinical factors limiting the choice between OACs. Of patient's preferences, the most important was the attitude towards co-payments of OACs. Patients' opinions on monitoring of treatment, dosing and antidote availability were also mentioned by the interviewees. The choice of an OAC in AF was patient-centered as all interviewees expressed that patient's opinion affect the choice.

\section{Introduction}

Atrial fibrillation (AF), the most common cardiac arrhythmia, is associated with a two-fold increase in stroke risk [1]. In the European Union, the number of individuals aged 55 years and older with AF is expected to more than double from 2010 to 2060 [2]. While vitamin K antagonists (VKAs), warfarin in particular, have been the mainstay of anticoagulation therapy in AF, direct oral anticoagulants (DOACs) rivaroxaban, dabigatran, apixaban and edoxaban now provide an alternative [3-6]. In fact, current European guidelines recommend the use of DOACs for eligible AF patients in preference to VKAs [1]. Besides their fixed dosing without the need of regular laboratory monitoring, DOACs have a favourable risk-benefit profile, including a lower risk of intracranial haemorrhage, compared to warfarin [7].

The European guidelines on management of AF recommend considering patients' preferences when making treatment decisions about, for example, medications [1]. In shared decision making, patients' preferences are taken into account, and the treatment decision is consensual between the patient and the physician [8]. Shared decision making is considered appropriate for stroke prevention in AF because of the availability of several treatment options with different risk-benefit profiles. Recent physician surveys and interviews suggest that physicians consider patient participation in decision 
making on the use of oral anticoagulants (OACs) in AF important [9-12]. Physicians also report clinical characteristics of the patient [13], risk of adverse events [11], their own knowledge, experience [10] and preferences [14] to be important in decision making. Database studies have identified mainly clinical factors, such as estimated stroke risk [15,16], age [16-19] and other cardiovascular diseases $[16,17,19-21]$ as factors affecting the choice of an OAC. These studies have also found lower socioeconomic status [18-20] and poorer medication coverage [15,21] to favour the use of VKAs.

There is no information on how patients participate in the decision making on OACs in Finland where the setting is different to many other countries. For example, the Finnish guidelines do not prefer use of DOACs over VKAs but in most cases recommend patient-specific selection between the types of OACs [22]. We conducted a qualitative study among Finnish physicians in primary and specialized health care working in the public sector to better understand the factors affecting physicians' choice of an $\mathrm{OAC}$ in $\mathrm{AF}$ after the treatment decision has been made. We have previously reported results on the effect of clinical and non-clinical factors (e.g., need of cardioversion, contraindications, renal function, co-payments) on the choice of an OAC [23]. In this paper, we focus on the participation of patients in this choice as perceived by physicians.

\section{Methods}

Context. In Finland, the current clinical guidelines recommend patient-specific selection between warfarin (the only VKA available in Finland) and DOACs in AF to be based on the evaluation of medications' properties and the patient's opinion [22]. DOACs are preferred if anticoagulation is needed only for short-term (e.g., for cardioversion). Among the disadvantages of DOACs, the guideline lists the lack of a specific antidote for other DOACs than dabigatran. Also, the cost of DOACs is among the disadvantages. At the time of the interviews (November 2016-February 2017), the difference in the monthly cost shared by the patient between warfarin and DOACs was nearly $€ 50$ 
(only small cost differences between DOACs). In addition, not all patients with AF were entitled to the reimbursement for DOACs, increasing the difference to almost $€ 90$. The quality of warfarin treatment, measured as time in therapeutic range, has been reported to be good in Finland compared to many non-Nordic countries $[24,25]$.

In addition to the regulatory monitoring of pharmaceutical marketing, the pharmaceutical industry self-regulates its marketing in Finland [26]. It is forbidden to offer physicians any financial incentives, including promotional gifts related to prescription-only medications. Training and medical representations by the pharmaceutical industry are also regulated. No incentives for prescribing certain medications or managing chronic illnesses are offered by the public healthcare system either.

Sampling, recruitment and data collection. Using purposive sampling, we recruited participants from 12 primary health care organizers with and without anticoagulation clinics and 13 clinics in six special healthcare hospitals in Central and Eastern Finland. Physicians were recruited by email personally or through administration, chief physicians, medical directors or contact persons named by the organizations. Recruitment continued until data saturation [27] (i.e., after no new themes emerged in interviews). The study included physicians who were working in primary or specialized healthcare (cardiology, neurology and internal medicine) in the public sector and were willing to participate in the study. The three medical specialties were chosen because they typically treat patients with AF.

Data were collected through semi-structured interviews [28]. We developed an interview guide with open-ended questions based on previous literature [9,10,12-14] (Supporting information). The guide was pretested in three pilot interviews that were not included in the data. The interviewer also asked follow-up questions prompted by participant's responses, and points outside the guide were discussed if introduced by the participant. Interviews were recorded with participants' permission and 
transcribed verbatim by an independent transcription service. One researcher (EA) conducted all interviews.

In total, 13 face-to-face interviews at physicians' work places and four phone interviews (25-65 min. each) were conducted. The sample included eight general practitioners (GPs) from seven primary healthcare organizers and nine specialists (two from neurology, five from cardiology and two from internal medicine) from six hospitals (Table 1). Three GPs worked in an organization with an anticoagulation clinic.

The interviewees had practiced medicine from less than a year to $>30$ years (Table 1). In addition, the extent of experience with DOACs varied across the physicians from writing only a few DOAC prescriptions to prescribing them weekly. At the time of the interviews, none of the interviewees had prescribed edoxaban.

Data analysis. One researcher (EA) compared the transcripts of the interviews with the recordings and analysed de-identified data to find factors affecting the choice of an OAC. The data were thematically analysed using both deductive and inductive approaches [29]. In deductive approach, factors previously reported to affect the choice were looked for in the data (e.g., co-payment, monitoring and patients' preferences). In inductive approach, the data were searched to find new influential factors. The new factors found inductively included indication (the need for cardioversion in particular), physicians' past OAC prescribing habits, characteristics of clinical trials, and patients' entitlement to reimbursement affecting the amount of co-payment. 
Ethics and consent statement. The study complied with the national ethical principles of research [30]. According to the instructions, this study did not require ethical approval. Willingness to participate in the interviews was seen as a consent to participate in the study.

\section{Results}

Based on the interviews, when there were no contraindications or other clinical factors limiting the choice between OACs (e.g., renal function, interactions with co-medication), patient's opinion was the most influential factor. There were no great differences between the interviewed GPs and specialists in the effect of patients' preferences on the decision making, overall, and all the interviewees expressed that patients' opinions affect the choice. When physicians were asked generally about prescribing of OACs and the process of choosing an $\mathrm{OAC}$, all but two physicians mentioned patient participation in the decision making unprompted. In addition, when asked which factors ease the choice between OACs, six physicians mentioned patients' opinion.

"Perhaps you do to steer the conversation into a specific direction. Even if there aren't any contraindications, there are still arguments that support one way over the other. Well, there's the 40year-old relatively healthy man who has no risk of bleeding. In that case, the patient gets to choose whether he wants to take medication once or twice a day." (S04, cardiology)

Of patients' preferences, the most important was their views about the co-payment of OACs (Table 2). All the interviewees said that DOACs are too expensive for some patients for whom the copayment is the deciding factor. Even though some of the interviewees had strong preferences for DOACs, they prescribed warfarin if the patient considered DOACs too expensive. 
"If it's a question of price, the choice is made in favour [of warfarin]." (GP08)

Patients' attitude towards the monitoring of warfarin treatment was mentioned in ten interviews (Table 2). According to the interviewees, some patients want to use DOACs because they find regular monitoring of international normalized ratio (INR) inconvenient. Patients may also experience difficulties in having their INR controlled due to long distances (e.g., for not owning a car), poor health (going to INR tests constitutes a burden) or employment (difficulties combining work and going to INR tests, work-related travels). However, not all patients view INR monitoring as a negative attribute.

"INR tests are not a problem for every patient. It might even be the other way around. Then a taxi bringing you to the town center is the highlight of the week or month. It gives the patient the chance to go shopping and see other people." (S06, cardiology)

Besides preferences affecting the choice between warfarin and DOACs, some interviewees mentioned patients' preferences that can affect the choice between different DOACs (Table 2). Ten interviewees said they took into account patients' opinion about the dosing frequency (i.e., taken once or twice a day). In addition, six interviewees told patients may wish to be prescribed a DOAC with a specific antidote available. However, there were differences between the interviewees whether they offered all DOACs to patients or chose which DOAC to offer alongside warfarin.

"Some go for [a medication taken] once a day. Then again, some opt specifically for a medication with an existing antidote." (S03, neurology) 
Based on the interviews, the most common reason why physicians included patients in the decision making was the large difference in the co-payments between warfarin and DOACs. All interviewees mentioned the importance of co-payment to some patients, and a few physicians mentioned especially that they prescribe each patient an OAC the patient can afford to use. In addition, three physicians felt that patients adhere better to their treatment when they have participated in the decision making.

Another reason why patient preferences are so influential might be that the different OACs were viewed equally effective: 11 physicians considered high quality warfarin treatment as effective as DOACs, although 11 physicians felt DOACs to be safer than warfarin. In addition, 10 physicians mentioned that they did not see great differences between different DOACs or that they have not been directly compared and, therefore, none of them can be said to be better than the others. However, some physicians expressed they preferred a specific anticoagulant in some situations and in those cases they tried to steer the conversation towards their choice or offer only one or some of the DOACs to the patient.

Even though our main focus was on the initiation of OAC treatment, the interviewees were also asked about switching of OACs. The influence of patients' opinions was evident also in these responses: the most frequently reported reasons for switching were patient request in addition to poor quality of warfarin therapy. Thirteen physicians told that they had switched patients from warfarin to a DOAC because patients, for example, found DOACs easier to administer or INR monitoring inconvenient (Table 2). Seven interviewees had switched patients from a DOAC to warfarin, mainly due to the high co-payment of DOACs. 


\section{Discussion}

Based on the 17 interviews conducted in our study, the choice of an OAC in AF is patient-centered, particularly when choosing between warfarin and a DOAC, and the patient's preferences strongly affect the decision making if there are no contraindications or other clinical factors limiting the choice. According to the interviewed physicians, warfarin's markedly lower co-payment is a deciding factor for some patients. In addition, patients may have preferences regarding the dosing frequency or availability of a specific antidote regarding DOACs. The main reason for physicians to involve the patient in the decision making seems to be to enhance treatment success.

Our findings on the importance of patients' opinions accord with recent studies on decision making on anticoagulation therapy in AF. In their study, Kirley et al. interviewed physicians about decision making on anticoagulation management in patients with AF in general [10]. Patient convenience and preferences were found to be important to physicians when considering anticoagulation. In addition, co-payment emerged as an important barrier to DOAC use. In another US study, physicians from a single medical centre were surveyed about factors influencing their choice between warfarin and dabigatran for patients with AF [13]. Patient request was the third most common reason, after factors related to patient convenience, to prescribe dabigatran to patients without a previous OAC and the fourth most common reason among patients using warfarin after factors related to patient convenience and unstable INR. The co-payment of DOACs was important also in this study as cost was the most common reason for not prescribing dabigatran.

Similar results about the importance of the patient's role have been reported also from other countries. In a Canadian survey for internal medicine residents, patient convenience was the second most important factor when choosing an $\mathrm{OAC}$ for patients with $\mathrm{AF}$ after adverse events [11]. In Italy, 70\% of internal medicine centers participating in a survey on DOACs regarded the patient's preference to be highly relevant when prescribing DOAC therapy in AF [9]. In a Norwegian focus group study 
among hospital physicians, patients' preferences were reported to be important factors in decision making although patients' characteristics were most influential factors when choosing an OAC [12].

Palacio et al. reported that patients potentially exposed to a decision on anticoagulation (i.e., patients at risk of AF or already on OACs) prefer to take part in the decision making [31]. This accords with the patients' participation described by the physicians interviewed in our study. However, in the survey by Choi et al., only $25 \%$ of warfarin users and $37 \%$ of dabigatran users had discussed with their physician about treatment options when initiating anticoagulation [32]. The preceding study was conducted in 2011. It is possible that patients' participation in decision making on OACs has increased after more DOACs have entered the market and DOAC use has increased.

Results from patient-based studies support our observations on the importance of OAC attributes other than the effect on stroke and bleeding risks. According to the review by Wilke et al., patients prefer more easily administered treatments if the treatments' clinical effects are similar [33]. For example, in a German study, patients overall preferred a treatment with no requirement for INR monitoring or dose adjustments, no interactions with food, and once-daily dosing [34]. In a Dutch study, the most important reason for patients to switch to a DOAC was that frequent laboratory monitoring is not required [35]. However, the results on patient preferences have been mixed [36]. For example, patients' attitudes towards monitoring may vary considerably [37], and some patients using warfarin are reluctant to switch to a DOAC because the lack of laboratory monitoring [38]. This accords with our interviews where physicians mentioned both patients' negative and positive attitudes towards INR monitoring. In an Italian study of VKA users, the majority was worried about using a DOAC for which no antidote was available [38]. Accordingly, some of our interviewees brought up the importance of the availability of a specific antidote for some patients. As DOACs' reimbursement rates have been raised in Finland after our study period causing the difference in co-payments to 
decrease for patients entitled to reimbursement [39], it is possible that the importance of these OAC attributes has increased in decision making.

Patients' differing preferences reported in previous studies [36-38] and in our study emphasize the importance of shared decision making when choosing an OAC. As different patients have different preferences, physicians should ask their patients which attributes are important to them. Application of shared decision making could improve patient adherence to treatment [40].

Our study has limitations. Firstly, the number of interviewed physicians is small. However, our sample size is similar to that of previous qualitative studies (range 7 to 12 interviewees $[10,12]$ ). Furthermore, data saturation was reached. Conversely, although we reached theme saturation, we did not reach meaning saturation in all the themes emerging in the interviews [27]. For example, there was not enough evidence to draw conclusions on the association between physicians' prescribing frequency and shared decision making. Larger and quantitative studies are needed to explore this and the generalizability of the results to physicians in Finland and elsewhere. Secondly, we did not conduct any interviews among patients with AF to ascertain their participation in the decision making about OACs. Further studies are needed to study whether patients feel that their preferences are taken into account by their physicians and whether this impacts their adherence. Another limitation of our study is that only one researcher analysed the data, although continuous discussions were done among the research group to reflect the findings.

According to the views of the interviewed physicians, AF patients participate in the choice of their OAC. The interviewed physicians took into consideration patients' preferences in particular when choosing between warfarin and a DOAC. This was mainly due to the difference in the costs of these medications shared by the patient but also to patients' preferences regarding INR monitoring. When 
choosing between DOACs, some physicians also took into account patients' preferences on dosing frequency and availability of a specific antidote. The main reason for considering patients' preferences was to enhance the success of treatment.

\section{Acknowledgements}

Part of the results presented in the article has been previously published in the Finnish Medical Journal in Finnish [41]. We want to thank all the interviewed physicians for agreeing to participate in the study. We also thank Arja Helin-Salmivaara, Helena Kastarinen and Jenni Ilomäki for their valuable comments during the design phase of this study.

Table 1. Characteristics of the 17 physicians

\begin{tabular}{|l|l|}
\hline Characteristic & $\mathrm{n}$ \\
\hline Sex & \\
\hline Male & 14 \\
\hline Female & 3 \\
\hline Working years & \\
\hline Less than 5 years & 6 \\
\hline $5-10$ years & 2 \\
\hline $11-20$ years & 2 \\
\hline Over 20 years & 7 \\
\hline Speciality & \\
\hline Cardiology & $5^{*}$ \\
\hline Neurology & 2 \\
\hline Internal medicine & 2 \\
\hline General medicine & 3 \\
\hline None & 5 \\
\hline Frequency of treating patients with AF & \\
\hline Daily & 11 \\
\hline Weekly & 5 \\
\hline Monthly & 0 \\
\hline Less than monthly & 1 \\
\hline
\end{tabular}

$* 2$ of 5 were specialists in cardiology and internal medicine

$\mathrm{AF}$ : atrial fibrillation

This article is protected by copyright. All rights reserved. 
Table 2. Patient preferences affecting the oral anticoagulant choice mentioned by the 17 physicians

\begin{tabular}{|l|l|}
\hline Preferences & $\mathrm{n}$ \\
\hline When initiating treatment & \\
\hline Co-payments & 17 \\
\hline Need for treatment monitoring & 10 \\
\hline Dosing & 10 \\
\hline Availability of an antidote & 6 \\
\hline When switching treatment & \\
\hline Co-payments & 7 \\
\hline Need for treatment monitoring & 4 \\
\hline Convenience of treatment & 4 \\
\hline
\end{tabular}

\section{References}

1 Kirchhof P, Benussi S, Kotecha D, Ahlsson A, Atar D, Casadei B, et al. 2016 ESC Guidelines for the management of atrial fibrillation developed in collaboration with EACTS. Europace 2016;18:1609-78. Doi: 10.1093/europace/euw295

2 Krijthe BP, Kunst A, Benjamin EJ, Lip GY, Franco OH, Hofman A, et al. Projections on the number of individuals with atrial fibrillation in the European Union, from 2000 to 2060. Eur Heart J 2013;34:2746-51. Doi: 10.1093/eurheartj/eht280

3 Connolly SJ, Ezekowitz MD, Yusuf S, Eikelboom J, Oldgren J, Parekh A, et al. Dabigatran versus warfarin in patients with atrial fibrillation. N Engl J Med 2009;361:1139-51. Doi:

10.1056/NEJMoa0905561

4 Patel MR, Mahaffey KW, Garg J, Pan G, Singer DE, Hacke W, et al. Rivaroxaban versus warfarin in nonvalvular atrial fibrillation. N Engl J Med 2011;365:883-91. Doi: 10.1056/NEJMoa1009638

5 Granger CB, Alexander JH, McMurray JJ, Lopes RD, Hylek EM, Hanna M, et al. Apixaban versus warfarin in patients with atrial fibrillation. N Engl J Med 2011;365:981-92. Doi:

10.1056/NEJMoa1107039

6 Giugliano RP, Ruff CT, Braunwald E, Murphy SA, Wiviott SD, Halperin JL, et al. Edoxaban versus warfarin in patients with atrial fibrillation. N Engl J Med 2013;369:2093-104. Doi:

10.1056/NEJMoa1310907

7 Ruff CT, Giugliano RP, Braunwald E, Hoffman EB, Deenadayalu N, Ezekowitz MD, et al. Comparison of the efficacy and safety of new oral anticoagulants with warfarin in patients with atrial fibrillation: a meta-analysis of randomised trials. Lancet 2014;383:955-62. Doi: 10.1016/S01406736(13)62343-0 
8 Seaburg L, Hess EP, Coylewright M, Ting HH, McLeod CJ, Montori VM. Shared decision making in atrial fibrillation: where we are and where we should be going. Circulation 2014;129:704-10. Doi: 10.1161/CIRCULATIONAHA.113.004498

9 Pignatelli P, Pastori D, Perticone F, Corazza GR, Violi F, ARAPACIS (Atrial Fibrillation Registry for Ankle-Brachial Index Prevalence Assessment-Collaborative Italian Study) Study group. Lights and shadows in the management of old and new oral anticoagulants in the real world of atrial fibrillation by Italian internists. A survey from the Atrial Fibrillation Registry for Ankle-Brachial Index Prevalence Assessment-Collaborative Italian Study. Eur J Intern Med 2015;26:31. Doi: 10.1016/j.ejim.2015.06.007

10 Kirley K, GouthamRao, Bauer V, Masi C. The role Of NOACs in atrial fibrillation management: a qualitative study. J Atr Fibrillation 2016;9:1416. Doi: 10.4022/jafib.1416

11 Moulson N, McIntyre WF, Oqab Z, Yazdan-Ashoori P, Quinn KL, van Oosten E, et al. The anticoagulation choices of internal medicine residents for stroke prevention in non-valvular atrial fibrillation. Postgrad Med J 2017;93:308-12. Doi: 10.1136/postgradmedj-2016-134159

12 Eek AK, Oie E, Granas AG. Prescribing of NOACs has outnumbered warfarin: exploring how physicians choose anticoagulant treatments. Eur J Clin Pharmacol 2018;74:323-30. Doi: 10.1007/s00228-017-2374-4

13 Huang C, Siu M, Vu L, Wong S, Shin J. Factors influencing doctors' selection of dabigatran in non-valvular atrial fibrillation. J Eval Clin Pract 2013;19:938-43. Doi: 10.1111/j.13652753.2012.01886.x

14 Oqab Z, McIntyre WF, Quinn KL, Lamb T, Quadros K, Yazdan-Ashoori P, et al. Resident physicians choices of anticoagulation for stroke prevention in patients with nonvalvular atrial fibrillation. Can J Cardiol 2016;32:824-8. Doi: 10.1016/j.cjca.2015.08.004

15 Lauffenburger JC, Farley JF, Gehi AK, Rhoney DH, Brookhart MA, Fang G. Factors driving anticoagulant selection in patients with atrial fibrillation in the United States. Am J Cardiol 2015;115:1095-101. Doi: 10.1016/j.amjcard.2015.01.539

16 Gundlund A, Staerk L, Fosbol EL, Gadsboll K, Sindet-Pedersen C, Bonde AN, et al. Initiation of anticoagulation in atrial fibrillation: which factors are associated with choice of anticoagulant? J Intern Med 2017;282:164-74. Doi: 10.1111/joim.12628

17 Olesen JB, Sorensen R, Hansen ML, Lamberts M, Weeke P, Mikkelsen AP, et al. Non-vitamin K antagonist oral anticoagulation agents in anticoagulant naive atrial fibrillation patients: Danish nationwide descriptive data 2011-2013. Europace 2015;17:187-93. Doi: 10.1093/europace/euu225

18 Sholzberg M, Gomes T, Juurlink DN, Yao Z, Mamdani MM, Laupacis A. The influence of socioeconomic status on selection of anticoagulation for atrial fibrillation. PLoS One 2016;11:e0149142. Doi: 10.1371/journal.pone.0149142 
19 Rodriguez-Bernal CL, Hurtado I, Garcia-Sempere A, Peiro S, Sanfelix-Gimeno G. Oral anticoagulants initiation in patients with atrial fibrillation: real-world data from a population-based cohort. Front Pharmacol 2017;8:63. Doi: 10.3389/fphar.2017.00063

20 Desai NR, Krumme AA, Schneeweiss S, Shrank WH, Brill G, Pezalla EJ, et al. Patterns of initiation of oral anticoagulants in patients with atrial fibrillation- quality and cost implications. Am J Med 2014;127:82.e1. Doi: 10.1016/j.amjmed.2014.05.013

21 Baik SH, Hernandez I, Zhang Y. Evaluating the initiation of novel oral anticoagulants in Medicare beneficiaries. J Manag Care Spec Pharm 2016;22:281-92. Doi: 10.18553/jmcp.2016.22.3.281

22 Aarnio E, Huupponen R, Korhonen MJ. Important factors affecting the choice of an oral anticoagulant may be missed in database studies. J Intern Med 2018;283:214-5. Doi:

10.1111/joim. 12686

23 Atrial fibrillation. Current Care Guidelines. Working group set up by the Finnish Medical Society Duodecim and the Finnish Cardiac Society. Helsinki: The Finnish Medical Society Duodecim. Available at: www.kaypahoito.fi. Accessed Jun 18, 2018

24 Hallinen T, Soini EJ, Asseburg C, Kuosmanen P, Laakkonen A. Warfarin treatment among Finnish patients with atrial fibrillation: retrospective registry study based on primary healthcare data. BMJ Open 2014;4:004071. Doi: 10.1136/bmjopen-2013-004071

25 Wallentin L, Yusuf S, Ezekowitz MD, Alings M, Flather M, Franzosi MG, et al. Efficacy and safety of dabigatran compared with warfarin at different levels of international normalised ratio control for stroke prevention in atrial fibrillation: an analysis of the RE-LY trial. Lancet 2010;376:975-83. Doi: 10.1016/S0140-6736(10)61194-4

26 Pharma Industry Finland Code of Ethics. Available at: www.pif.fi/en/medicine/marketing. Accessed Jun 6, 2018

27 Hennink MM, Kaiser BN, Marconi VC. Code saturation versus meaning saturation: how many interviews are enough? Qual Health Res 2017;27:591-608. Doi: 10.1177/1049732316665344

28 Dicicco-Bloom B, Crabtree BF. The qualitative research interview. Med Educ 2006;40:314-21. Doi: 10.1111/j.1365-2929.2006.02418.x

29 Vaismoradi M, Turunen H, Bondas T. Content analysis and thematic analysis: Implications for conducting a qualitative descriptive study. Nurs Health Sci 2013;15:398-405. Doi: 10.1111/nhs. 12048

30 Ethical review in human sciences. Available at: www.tenk.fi/en/ethical-review-in-human-sciences. Accessed Jun 7, 2018

31 Palacio AM, Kirolos I, Tamariz L. Patient values and preferences when choosing anticoagulants. Patient Prefer Adherence 2015;9:133-8. Doi: 10.2147/PPA.S64295 
32 Choi JC, Dibonaventura MD, Kopenhafer L, Nelson WW. Survey of the use of warfarin and the newer anticoagulant dabigatran in patients with atrial fibrillation. Patient Prefer Adherence 2014;8:167-77. Doi: 10.2147/PPA.S56187

33 Wilke T, Bauer S, Mueller S, Kohlmann T, Bauersachs R. Patient preferences for oral anticoagulation therapy in atrial fibrillation: a systematic literature review. Patient 2017;10:17-37. Doi: 10.1007/s40271-016-0185-9

34 Bottger B, Thate-Waschke IM, Bauersachs R, Kohlmann T, Wilke T. Preferences for anticoagulation therapy in atrial fibrillation: the patients' view. J Thromb Thrombolysis 2015;40:40615. Doi: $10.1007 / \mathrm{s} 11239-015-1263-\mathrm{x}$

35 Boom MS, Berghuis EM, Nieuwkerk PT, Pinedo S, Buller HR. When do patients prefer a direct oral anticoagulant over a vitamin K antagonist? Neth J Med 2015;73:368-72.

36 Loewen PS, Ji AT, Kapanen A, McClean A. Patient values and preferences for antithrombotic therapy in atrial fibrillation. A narrative systematic review. Thromb Haemost 2017;117:1007-22. Doi: 10.1160/TH16-10-0787

37 Bajorek B, Saxton B, Anderson E, Chow CK. Patients' preferences for new versus old anticoagulants: a mixed-method vignette-based study. Eur J Cardiovasc Nurs 2018;17:429-38. Doi: $10.1177 / 1474515117739618$

38 Barcellona D, Luzza M, Battino N, Fenu L, Marongiu F. The criteria of the Italian Federation of Thrombosis Centres on DOACs: a "real world" application in nonvalvular atrial fibrillation patients already on vitamin K antagonist. Intern Emerg Med 2015;10:157-63. Doi: 10.1007/s11739-014-11557

39 Medicinal Products Database. Available at: www.kela.fi. Accessed Jun 18, 2018

40 Lofland JH, Johnson PT, Ingham MP, Rosemas SC, White JC, Ellis L. Shared decision-making for biologic treatment of autoimmune disease: influence on adherence, persistence, satisfaction, and health care costs. Patient Prefer Adherence 2017;11:947-58. Doi: 10.2147/PPA.S133222

41 Aarnio E, Merikoski M, Helin-Salmivaara A, Huupponen R, Hämeen-Anttila K, Ilomäki J, et al. Hinta ohjaa oraalisen antikoagulantin valintaa eteisvärinäpotilaalle [in Finnish without an English abstract]. Finnish Medical Journal 2017;72:1792-5. 